\title{
The Rhetorical Structure of Literature Reviews in Egyptian- Authored English Research Articles in Linguistics
}

Hend Rabie ${ }^{1}$ \& Deena Boraie ${ }^{2}$

${ }^{1}$ Fayoum University, Egypt \& ${ }^{2}$ The American University in Cairo, Egypt

\begin{tabular}{|c|c|}
\hline ARTICLE INFO & \multirow{14}{*}{$\begin{array}{l}\text { ABSTRACT } \\
\text { The present paper seeks to examine the rhetorical structure of the } \\
\text { literature review (LR) sections of English research articles (RAs) } \\
\text { written by Egyptian researchers in the field of linguistics. For this } \\
\text { purpose, a sample of ten LRs was selected from RAs published in } \\
\text { local and international English-medium journals in linguistics } \\
\text { between } 2013 \text { and } 2019 \text {. The study deployed hybrid techniques and } \\
\text { approaches for data collection (random/non-random sampling) and } \\
\text { data analysis } \\
\text { qualitative/quantitative). Findings showed rhetorical variation in the } \\
\text { LRs written by both groups, especially concerning Move } 2 \text { and Move } \\
3 \text { that were used more frequently in the international sample than in } \\
\text { the local one, where the focus was on Move 1. In addition, some new } \\
\text { steps emerged. The findings also shed light on the problems within } \\
\text { the rhetorical structure of the LRs published locally, implying that the } \\
\text { lack of rhetorical knowledge is one of the major reasons that hinder } \\
\text { writing professional LRs. This paper contributes to a better } \\
\text { understanding of the generic structure of RA LRs by proposing a } \\
\text { modified version of Kwan's (2006) model. It has pedagogical } \\
\text { implications for teaching Egyptian and apprentice researchers how to } \\
\text { write more effective RA LRs. Future studies on a larger corpus of } \\
\text { complete RAs written by Egyptian and international researchers in } \\
\text { soft and hard sciences are needed to provide more generalizable } \\
\text { findings. }\end{array}$} \\
\hline & \\
\hline Received Dec 30, 2020 & \\
\hline Revised Jan 30, 2021 & \\
\hline Accepted Feb 28, 2021 & \\
\hline Keywords: & \\
\hline Research Article & \\
\hline Literature Reviews, & \\
\hline Genre Analysis, & \\
\hline Rhetorical Structure, & \\
\hline Conflict of Interest: & \\
\hline None & \\
\hline Funding: & \\
\hline None & \\
\hline
\end{tabular}

Corresponding Author: Hend Rabie, Fayoum University, Egypt. E-mail: hra02@fayoum.edu.eg.

(C) Hend Rabie, Deena Boraie

This is an open access article under the CC BY-SA 4.0 international license.

\section{Introduction}

RAs have sparked the research interest, especially after the pressing need for academics to publish in highimpacted international journals to get academic degrees or be promoted in faculty positions (Flowerdew \& Wang, 2016; Habibie, 2019; Nhat, 2019). However, the LR has been paid scant attention compared to the great bulk of research undertaken on RA different sections. This paucity of research on RA LRs may be attributed to a number of reasons. A strong reason is that most models of analyzing RAs' introductions (Lewin, Fine, \& Young, 2001; Samraj, 2002; Swales, 1990) and theses' introductions (Bunton, 2002) have referred to the LR as part of the introduction section/chapter, claiming that Introduction-Method-ResultsDiscussion (IMRD) is the standard pattern. However, many studies have pointed out that RAs can deviate from the IMRD structure (Lin \& Evans, 2012; McGrath \& Kuteeva, 2012), indicating that IntroductionLiterature review-Method-Results-Discussion (ILrMRD) is another RA pattern.

Another possible reason may be related to the nature of the LR as it is looked at negatively. For example, it was viewed as "a boring but necessary chore" (Feak \& Swales, 2009, p. 9). However, this negative comment has been countered by many researchers who have depicted the LR positively, stressing its important role in 
justifying the significance of one's research and highlighting the researcher's highly critical skills. This in return paves the way for publishing in high-impact international journals (Kwan, 2006).

A third motive is that the LR is considered as one of the most complex difficult sections/chapters researchers have to write (Huang \& Zhang, 2016; Inoue-Smith, 2020; Swales \& Lindemann, 2002); it "is rhetorically a highly demanding part-genre that generally presents greater rhetorical problems than methods and results sections" (Swales \& Lindemann, 2002, p. 117). In addition, it is considered as one of the most criticized sections by reviewers during the process of reviewing manuscripts for publication (Flowerdew, 2001; Tewksbury \& Mustaine, 2012).

Because the rhetorical structure of the LR cannot be expressed in terms of the rhetorical structures of the other sections as stated by Swales and Lindemann (2002), discussing it as part of any of these sections-even the introduction - is deficient and misleading and thus this necessitates analyzing it separately, a view that was confirmed by Kwan (2006) after comparing the rhetorical structure of a corpus of LR chapters to Bunton's (2002) revised CARS (Create a Research Space) model for analyzing thesis introductions.

Very few studies have been conducted on analyzing the LR (Chen, 2008, as cited in Jian, 2010; Hsiao \& Yu, 2012; Jian, 2010; Kwan, 2006), so more studies are needed to analyze RA LRs to achieve a better understanding of their rhetorical structure. In addition, no study has analyzed Egyptian-authored RA LRs in the field of linguistics. In order to fill-in these gaps, the present study seeks to investigate and compare the generic structure of a sample of Egyptian-authored linguistics RA LRs published in local and international English-medium journals.

\section{Literature Review}

\subsection{Genre Analysis}

In their seminal books, Swales (1990) and Bhatia (1993) define genre as communicative events featured by a number of communicative purposes approved and adopted by its community members. Genre analysis is a means of studying the formal and functional features of the language of the genre in an attempt to understand the communicative purposes it conveys (Bhatia, 2012). It enables inexperienced writers to acquire expertise and thus be more skillful and creative, producing high-quality professional writing (Bhatia, 1997; Loi \& Evans, 2010). Genre analysis can be conducted at either a macro or a micro level (Bunton, 2002). The macro level investigates the rhetorical structure of a text (moves analysis), while the micro level deals with the linguistic features (lexical and syntactic analysis). Move analysis, the focus of the present study, depends on dividing the text into segments (moves) where each segment expresses an idea/a theme, reflecting a particular communicative function and contributing to the holistic communicative function of the genre as a whole (Parodi, 2010). These segments are referred to as "the building blocks of texts" (Biber, Connor, \& Upton, 2007, p.9). Move analysis was first used by Swales (1990) to analyze RA introductions. Swales' pioneering work has inspired much research to investigate RA different sections including abstracts (Amnuai, 2019; Friginal \& Mustafam, 2017; Tankó, 2017), introductions (Lu, Casal, \& Liu, 2020; Lu, Yoon, \& Kisselev, 2021; Sheldon, 2011), methods (Cotos, Huffman, \& Link, 2017; Farnia \& Baratizade, 2020; Peacock, 2011), results (Basturkmen, 2009; Kurniawan \& Lubis, 2020; Lim, 2011), discussions (Amnuai \& Wannaruk, 2013; Basturkmen, 2012; Liu \& Buckingham, 2018), and conclusions (Jahangard, Rajabi, \& Khalaji, 2014; Yang \& Allison, 2003; Zamani \& Ebadi, 2016). However, the RA LR is still an under-researched area.

\subsection{The LR Section}

Reviewing the literature involves critiquing the literature and integrating the previous findings in a convincing argument that sheds light on the research gap and thus justifies the significance of the present research; it is more than a mere summary of the literature (Inoue-Smith, 2020; Rewhorn, 2018). This process requires deploying higher cognitive skills to collect, classify, summarize, analyze, relate, evaluate, and synthesize the literature (Rewhorn, 2018). The LR is also referred to as an indicator of one's academic proficiency and grasp of the literature on the topic under investigation (Huang \& Zhang, 2016). The LR can be a sub-genre when it is a part of another research such as a section/chapter in an RA/a thesis, and it can be a genre when it represents an independent piece of writing on its own such as a review article or a book review.

The LR is not only one of the most important sections to be written in an RA and in academic writing in general (Denney \& Tewksbury, 2013; Feak \& Swales, 2009; Inoue-Smith, 2020), but it is also one of the most challenging tasks (Badenhorst, 2018; Inoue-Smith, 2020). Although there are several textbooks and RAs that have discussed its different aspects (e.g., meaning and purpose), developed taxonomies for classifying it (Cooper, 1985), designed rubrics for evaluating it (Boote \& Beile, 2005), and divided it into 
types (Feak \& Swales, 2009; Fink, 2014), the LR has been rarely discussed from genre analysis perspective because it was not dealt with as a separate section (Hsiao \& Yu, 2012; Kwan, 2006; Tseng, 2018).

\subsection{The Rhetorical Structure of the LR}

In 2006, Kwan postulated a three-move model for analyzing the rhetorical structure of PhD LR chapters. She found that Moves 1 and 2 outnumbered Move 3 and that Strategies 1A, 2A, and 3A were the most used strategies in their corresponding moves, but none of them was obligatory.

Table 1. Kwan's (2006) Model for Analyzing LR Chapters

\begin{tabular}{lc}
\hline Move 1 & Establishing one part of the territory of one's own research by \\
\hline Strategy A\# & Surveying the non-research-related phenomena or knowledge claims \\
\hline Strategy B\# & Claiming centrality \\
\hline Strategy C & Surveying the research-related phenomena \\
\hline Move 2 & Creating a research niche (in response to Move 1) by: \\
\hline Strategy A & Counter-claiming \\
\hline Strategy B & Gap-indicating \\
\hline Strategy C & Asserting confirmative claims about knowledge or research practices \\
\hline Strategy D & surveyed \\
\hline Strategy E & Asserting the relevancy of the surveyed claims to one's own research \\
\hline Move 3 (optional) & Occupying the research niche by announcing: \\
\hline Strategy A & Research aims, focuses, research questions or hypotheses * \\
\hline Strategy B & Theoretical positions/theoretical frameworks * \\
\hline Strategy C & Research design/processes * \\
\hline Strategy D & Interpretations of terminology used in the thesis * \\
\hline
\end{tabular}

* Sub-strategy: justifying or claiming contributions of the announced claims

\# Strategy 1B tends to precede Strategy 1A when the two co-occur.

(Kwan, 2006, p. 51)

Other models were developed on the basis of Kwan's (2006) model for investigating the LR section/chapter. For instance, Jian (2010) analyzed the LR section in 40 English RAs and 40 Chinese RAs, using Swales' (1990), Kwan's (2006), and Chen's (2008, as cited in Jian, 2010) models as the basis for proposing a 4-move model (Establishing a thematic territory, Surveying and summarizing previous research, creating a research niche, and Occupying the research niche). Jian found that strategies 1A (making topic generalizations) and 4A (announcing aims/research questions) were used the most in their corresponding moves. However, strategy 2A (counter-claiming) had the least occurrence rate in the English LRs and disappeared from the Chinese LRs. In addition, it was found that Move 2 (Surveying and summarizing previous research) was obligatory as it occurred in all the instances of the investigated LRs.

Hsiao and $\mathrm{Yu}$ (2012) also analyzed 30 LR chapters of MA theses in TEFL written by Taiwanese graduates. On the basis of Kwan's model, they developed a 4-move model (Conceptualizing themes in a field, integrating previous works on the themes, relating previous works to the current study, and Advancing to one's own research). Agreeing with Kwan, the last move was used the least. In addition, the sub-moves in the first and last moves (i.e., surveying knowledge claims and announcing research aims) were used the most within their corresponding moves.

Among the four models, the current study adopted Kwan's model because it is more detailed and comprehensive than the other models and, thus, it best reflects the communicative functions of the LR. It is also more validated and applicable than the other models; it has been used in almost all the studies that analyzed the LR sections/chapters in both soft and hard disciplines (Chen \& Kuo, 2012; Gil-Salom \& SolerMonreal, 2014; Maulid, 2017; Soler-Monreal, 2015; Thompson, 2009; Xie, 2017). Chen \& Kuo (2012), for example, analyzed rhetorically 20 LR chapters in applied linguistics and found that Strategies 1A and 1C were used the most. Gil-Salom and Soler-Monreal (2014) also compared English and Spanish LR chapters. 
The findings revealed no significant structural differences between the two corpora. However, the Spanish LRs involved fewer strategies in Moves 2 and 3 than the English ones. Unlike Kwan's (2006) findings, the frequency occurrences of Strategies $1 \mathrm{~A}$ and $1 \mathrm{C}$ were equal in the English corpus and almost equal in the Spanish one. Agreeing with Kwan, move 3 was the least used move in both corpora.

Xie (2017) also followed Kwan's (2006) model to analyze 25 Chinese MA thesis LRs. Agreeing partially with Kwan, Xie found that Moves 1 and 2 appeared in all the theses, while Move 3 appeared in only 16 theses. In addition, Strategies 1A and 3A occurred the most in their corresponding moves. Unlike Kwan's findings, Strategies 1A and 1C were obligatory because they occurred in all the theses. Strategy 2B outnumbered Strategy 2A. Maulid also (2017) analyzed the LR chapters of four master's theses in the field of English as a foreign language (EFL) and found that strategy $1 \mathrm{~A}$ had the highest frequency occurrence.

\subsection{The Current Study}

Despite its significance, there is a dearth of research on the LR section compared to the abundant studies conducted on the other sections of the RA. In addition, no study, to the researchers' best knowledge, has analyzed the rhetorical structure of Egyptian-authored RA LRs. The present study, thus, seeks to address these gaps and answer the following research question:

- How are rhetorical moves/steps used in the LRs of Egyptian-authored ILrMRD linguistics RAs published in local and international English-medium journals?

To answer this question, a sample of ten Egyptian-authored linguistics RA LRs published in local and international English-medium journals between 2013 and 2019 were analyzed to identify the rhetorical variation between both sub-corpora, deploying a combination of genre-based and corpus-driven approaches.

\section{Method}

\subsection{Research Design}

This study is considered exploratory because there are very few studies that have discussed RA LRs in general and no study has discussed Egyptian-authored linguistics RA LRs in particular. The present study used mixed sampling techniques. It used a purposive sampling technique to collect the sub-corpus of Egyptian-authored RA LRs published in international journals and a simple random sampling technique to collect the sub-corpus of Egyptian-authored RA LRs published in local journals. The study used genre-based and corpus-driven approaches to analyze the LRs. According to McEnery and Hardie (2012), a corpus-driven approach can be used to analyze data, employing previous models; however, the researcher is free to add any modifications to these models in case they seem inefficient or do not account for the findings appropriately. In line with this view, a corpus-driven approach was used in this study to compare both sub-corpora and explore any new moves/steps that better reflect the rhetorical structure of the LRs under investigation without being restricted to Kwan's model. The identified moves/steps were analyzed qualitatively and quantitatively.

\subsection{Data Collection}

A sample of 10 Egyptian-authored linguistics RA LRs were taken from five top-rated local English-medium journals according to the Supreme Council of Universities and five international English-medium journals registered in Journal Citation Reports (2018) in Clarivate Analytics between 2013 and 2019, comprising a total of 16,326 words (see appendix A for the lists of the RAs from which the LRs were extracted). The corpus small size is due to the fact that the available Egyptian-authored international RAs (one sub-corpus) are few in their original population (international RAs) and this limitation restricts the size of the other subcorpus to get parallel sub-corpora. However, the corpus small size "is not especially problematic" because it is very specialized (Baker, 2010, p. 111), and it still meets Koester's (2010, p. 70) criteria "that any subcorpus within the corpus ... is represented by at least 1,000 words ..., and that every sub-corpus contains at least five ... different samples."

\subsection{Data Analysis}

The RAs were converted from PDF files into plain text files by AntFileConverter (Anthony, 2017), extracting the LR sections and coding them as Loc1-Loc5 for the local sub-corpus and Int1-Int5 for the international sub-corpus. Data analysis was conducted in two stages. In the first stage, the data was analyzed qualitatively. The moves/steps were identified according to their rhetorical functions, adopting a data-driven approach in light of Kwan's model and modifying or adding any new steps that did not fit the Kwan (2006) model. A rhetorical function can range from one clause to a cluster of sentences, while a sentence can express more than one communicative function. This implies that the basic unit of identifying moves and steps is the segment and that the moves/steps are not subject to the grammatical boundaries of sentences and paragraphs, 
i.e., a move/step can be realized in one clause or across a cluster of sentences (Lewin et al., 2001). The moves and steps were manually coded (e.g., $<\mathrm{M} 1>,<\mathrm{S} 1.1>$ ) in the plain text files. The first stage ends with postulating a data-driven model that efficiently reflects the rhetorical structure of the Egyptian-authored RA LRs in linguistics.

In the second stage, the data was analyzed quantitatively. The instances of moves'/steps' occurrences were counted to determine the major step realizations of each move across both sub-corpora. It is noteworthy that consecutive segments belonging to the same step type were counted as one instance of the step. The frequency occurrences of the moves/steps were retrieved within each text and across all texts via Notepad++'s (Ho, 2020) "find in files" function, then their percentages were computed and compared across both sub-corpora. The current study followed Soler-Monreal, Carbonell-Olivares, \& Gil-Salom's (2011) and Pho's (2013) criteria that a move/step is considered obligatory if it appears in equal to/more than $90 \%$ of the LRs, prototypical if it occurs in equal to/more than $60 \%$ and less than $90 \%$, and optional if it is identified in less than $60 \%$ of the LRs.

To ensure high inter-rater reliability, a sample of four texts were randomly selected and double coded by an external rater. Both codings were compared and any discrepancies were discussed till an agreement was reached. Finally, the rest of the texts (six LRs) were coded by the current researchers.

\section{Results}

4.1 Move Analysis of The LRs Using A Data-Driven Approach. The moves and their subsequent steps were identified according to their rhetorical functions, adopting a data-driven approach in light of Kwan's (2006) model. Based on data analysis, there was no change to Kwan's three moves (Establishing the territory of one's own research, creating a research niche, and Occupying the research niche). At the step level, some of Kwan's strategies (relabeled as steps) were kept without change, some were modified, and some new steps were added to better describe some of the segments in the data. The section is concluded with the new datadriven model. The rhetorical functions of each move and its subsequent steps (original, modified, and new) will be illustrated as follows (see Appendix B for examples from both sub-corpora to reflect the moves and their subsequent steps/sub-steps):

4.1.1 Establishing One Part of The Territory of One's Own Research. Move 1 provides background information on the issue/phenomenon under investigation; referring to its significance and discussing the relevant concepts, definitions, themes, models, theories, methodological procedures, and findings. Move 1 includes the three original strategies in Kwan's model and three new steps added by the researchers.

\subsubsection{Original Classification in Kwan's Model.}

4.1.1.1.1 Surveying the Non-Research-Related Phenomena or Knowledge Claims. This step describes the issue in question, discussing its relevant definitions and theoretical framework in an attempt to view it from different angles.

4.1.1.1.2 Claiming Centrality. This step indicates how a particular field of knowledge is significant and highly/recently researched, accounting for its selection for investigation.

4.1.1.1.3 Surveying the Research-Related Phenomena. This step delves into the details and findings of individual studies.

\subsubsection{New Steps Added to Kwan's Model.}

4.1.1.2.1 Approaching A Different (Sub)Theme and Summarizing A Group of Relevant Previous Studies. Given that the LR is replete with instances of previous studies, this step was added to Kwan's model to organize the way of displaying these studies. Rather than listing them, the writer finds relations among the surveyed studies and categorize them into groups according to the various (sub)themes they discuss to keep the reader focused, especially if the LR involves many themes and sub-themes. This step is usually followed by discussing individual studies relevant to each (sub)theme in more detail.

4.1.1.2.2 Evaluating Previous Studies. This step expresses the writer's stance through evaluating previous research, but this type of evaluation is different from the evaluation involved in the forthcoming sub-steps of justifying the research negatively or positively. This step does not imply using the cited paper in one's own study. The evaluation may be negative or positive.

The two latter steps require using higher cognitive skills, i.e., the ability to organize, classify, analyze, and critique. These two steps show that the writers do not suffice to use previous claims as they are; rather, they try to recycle them in a way that serves the sophisticated functions of the LR, reflecting its critical nature. 
4.1.1.2.3 Outlining the Structure of the LR. This step refers to the themes and sub-themes to be discussed within the LR. It guides the reader through the reading process. This step may occur once at the beginning of the section or many times before the different themes.

4.1.2 Creating A Research Niche. Compared to Move 1, the nature of Move 2 indicates viewing the LR as more than a summary of the literature. It involves a more sophisticated phase, and its writing requires using higher cognitive skills of analysis, critique, and synthesis to establish a series of relations to introduce one's own research. It is noteworthy that introducing one's own research as a reaction to the calls of the literature leads to a better perception and appreciation of its contribution. According to the researchers, this move is considered as the most important one because it represents a bridge between the previous findings and the expected ones.

\subsubsection{Original Steps in Kwan's Model.}

4.1.2.1.1 Asserting the Relevancy of The Surveyed Claims to One's Own Research. This step relates the literature (Move 1) to the current research (Move 3).

4.1.2.1.2 Abstracting or Synthesizing Knowledge Claims to Establish A Theoretical Position or A Theoretical Framework. This step is the last step before announcing the current research. It involves deploying the highest cognitive skill (create) in the revised Bloom's taxonomy (Anderson et al., 2001) since it aims at advancing a new theory/model. This step is usually accompanied by the forthcoming modified two sub-steps since delineating conclusions from the literature (the current step) requires referring back to the motivation beyond conducting the current research (the forthcoming modified two sub-steps).

4.1.2.2 New Step in Kwan's Model. Move 2 first three strategies (i.e., counter-claiming, gap-indicating, and confirmative claims) in Kwan's model were narrowed down into only one step (justifying one's research), comprising two sub-steps (providing negative justification and providing positive justification). This step justifies the study under focus. This justification, agreeing with Samraj (2002), is either negative or positive. The researchers find that Kwan's Strategy 2A (counter-claiming) should be embedded within Strategy 2B (gap-indicating) because the concept of a research gap in its broader sense is not restricted only to the lack of knowledge and rarity of the literature on a particular issue (an overlooked area). The gap may be a thorny issue that needs to be tackled, contradicting findings that need to be either supported or refuted (Kwan's counter-claiming), a point that needs further interpretation, a particular domain that is not fully discussed and thus needs to be covered, an issue that needs to be tackled from a new perspective, a variable that is less estimated and its effect needs to be measured, a problem that needs to be resolved, a new method that needs to be employed, a sample that needs to be more representative, new findings that need to be validated by further research, or a recommendation that needs to be taken into consideration. Many researchers and linguists discussed a similar point of view. Lewin et al. (2001, p. 44), for instance, classified a gap into "gaps of defect, scarcity, and obscurity." The first type denotes criticizing the previous literature by expressing its deficiencies and limitations. It is similar to Swales' (1990) and Kwan's (2006) counter-claiming step/strategy. However, the latter two types are used to establish the gap without explicit criticism. A similar meaning was also expressed by Samraj (2002, pp. 8-9), who explained that a gap can be realized in terms of "the contradictions among the findings from earlier studies [defect], ... the untested assumptions [obscurity], or lack of knowledge [scarcity]."

4.1.2.2.1 Justifying One's Research. This step justifies why a particular issue is significant and the writer expresses an evaluative stance, either negative or positive. It involves two sub-steps:

Providing negative justification. This sub-step justifies one's research on a negative basis by highlighting the research gap, either expressing scarcity of the researched issue within the literature or criticizing the literature (counter-claiming).

Providing positive justification. This sub-step justifies undertaking the research on a positive basis through stating the strengths of a particular theory or method to pave the way for its adoption in one's own study. It reflects Kwan's Strategy 2C (asserting confirmative claims about knowledge or research practices surveyed).

4.1.3 Occupying the Research Niche. The main communicative function of Move 3 is to introduce one's own research, showing how it contributes to the literature and thus highlighting its significance and originality.l

4.1.3.1 Changes to Original Steps in Kwan's Model. The gerund 'announcing' was omitted from Move 3 and a gerund form was added at the beginning of each step, instead.

4.1.3.1.1 Highlighting Research Aims, Focuses, Research Questions/Hypotheses, Or Contribution/Significance. This step states the objectives of the study, its main focus, and research questions. 
Research contribution/significance was added to the step because a research paper's contribution is logically one of its objectives. In many cases, this step is preceded by the Sub-step of providing negative justification to highlight the research contribution.

4.1.3.1.2 Positing Theoretical Positions/Theoretical Frameworks. In this step, the researcher announces the theoretical framework $\mathrm{s} /$ he is going to adopt in her/his study.

4.1.3.1.3 Presenting Research Design/Processes. In this step, the researcher briefly mentions the research design and the methodological procedures s/he is going to deploy in her/his research.

4.1.3.1.4 Providing Interpretations of The Terminology Used in The Current Research. This step involves discussing the terms of the study.

4.1.3.2 New Step Added to Kwan's Model.

4.1.3.2.1 Evaluating the Present Research. This step evaluates the expected strengths and/or weaknesses of one's own research.

4.1.4 The Data-Driven Model. Using the three moves in writing the LR achieves the targets of reviewing the literature, understanding any complicated relations, being aware of any involved drawbacks, introducing the new research, and highlighting its significance without being lost. In such a sense, the LR is considered as a journey to understand a new world of interwoven definitions, theories, complicated relations, debates, and findings.

Table 2. A Data-driven Model of Moves and Steps in Egyptian-authored Linguistics RA LRs

\begin{tabular}{|c|c|}
\hline Move 1 & Establishing one part of the territory of one's own research by \\
\hline Step 1.1 & Surveying the non-research-related phenomena or knowledge claims \\
\hline Step 1.2 & Claiming centrality \\
\hline Step 1.3 & $\begin{array}{l}\text { Approaching a different (sub)theme and summarizing a group of relevant } \\
\text { previous studies }\end{array}$ \\
\hline Step 1.4 & Surveying the research-related phenomena \\
\hline Step 1.5 & Evaluating previous studies \\
\hline Step 1.6 & Outlining the structure of the LR \\
\hline Move 2 & Creating a research niche (in response to Move 1) by \\
\hline Step 2.1 & Justifying one's research \\
\hline Sub-step $2.1 A$ & Providing negative justification \\
\hline Sub-step $2.1 B$ & Providing positive Justification \\
\hline Step 2.2 & Asserting the relevancy of the surveyed claims to one's own research \\
\hline Step 2.3 & $\begin{array}{l}\text { Abstracting or synthesizing knowledge claims to establish a theoretical } \\
\text { position or a theoretical framework }\end{array}$ \\
\hline Move 3 & Occupying the research niche by \\
\hline Step 3.1 & $\begin{array}{l}\text { Highlighting research aims, focuses, research questions/hypotheses, or } \\
\text { contribution/significance }\end{array}$ \\
\hline Step 3.2 & Positing theoretical positions/theoretical frameworks \\
\hline Step 3.3 & Presenting research design/processes \\
\hline Step 3.4 & Evaluating the present research \\
\hline Step 3.5 & Providing interpretations of the terminology used in the current research \\
\hline
\end{tabular}

Modifications and additions are in italics

4.2 Quantitative Genre Analysis. The distribution of moves was identified and compared across both subcorpora. Their frequency counts indicate the most used moves in each sub-corpus. Their percentages were used to classify them as obligatory, prototypical, or optional.

4.2.1 Move Distribution Across Both Sub-Corpora. 
Table 3. Frequency Counts of the Three Moves in the Local LRs

\begin{tabular}{lrrrrrccc}
\hline Moves & \multicolumn{5}{c}{ Local LRs } & & Total n. of & Total n. of LRs \\
& Loc1 & Loc2 & Loc3 & Loc4 & Loc5 & & move instances & $\begin{array}{c}\text { using the move } \\
(\%)\end{array}$ \\
\hline Move 1 & 15 & 14 & 7 & 1 & 7 & & $44(77.19 \%)$ & $5(100 \%)$ \\
Move 2 & 4 & 2 & - & 1 & 1 & $8(14.04 \%)$ & $4(80 \%)$ \\
Move 3 & 2 & 1 & - & 2 & - & $5(8.77 \%)$ & $3(60 \%)$ \\
\hline Total & 21 & 17 & 7 & 4 & 8 & 57 & \\
\hline
\end{tabular}

Table 4. Frequency Counts of the Three Moves in the International LRs

\begin{tabular}{|c|c|c|c|c|c|c|c|}
\hline \multirow[t]{2}{*}{ Moves } & \multicolumn{5}{|c|}{ International LRs } & \multirow{2}{*}{$\begin{array}{c}\text { Total n. of } \\
\text { move instances }\end{array}$} & \multirow{2}{*}{$\begin{array}{c}\text { Total n. of LRs } \\
\text { using the move } \\
(\%)\end{array}$} \\
\hline & Int1 & Int2 & Int3 & Int4 & Int5 & & \\
\hline Move 1 & 9 & 21 & 6 & 15 & 29 & $80(54.43 \%)$ & $5(100 \%)$ \\
\hline Move 2 & 11 & 11 & 2 & 9 & 9 & $42(28.57 \%)$ & $5(100 \%)$ \\
\hline Move 3 & 4 & 3 & 6 & 4 & 8 & $25(17 \%)$ & $5(100 \%)$ \\
\hline Total & 24 & 35 & 14 & 28 & 46 & 147 & \\
\hline
\end{tabular}

Tables 3 and 4 show that the moves' frequency occurrence in the international LRs was more than two times and half the number found in the local LRs (147 vs. 57). Agreeing with Kwan's (2006) findings, Move 1 was the most frequent move, followed by Moves 2 and 3 in both sub-corpora. The frequency occurrence of Move 1 in the international sample doubled its frequency occurrence in the local sub-corpus. However, these findings can be attributed to the different sizes of both sub-corpora. Moves 2 and 3 occurred in the international LRs much more than in the local LRs. Although Kwan's three moves occurred in all the international LRs, move 2 did not occur in one local LR and Move 3 did not occur in two local LRs. The variation between both groups shows that the writers of the international LRs are more aware of the LR rhetorical knowledge and writing conventions than their counterparts in the local sub-corpus. This also reflects how the writers of the international sub-corpus view the LR as a process of critique and interpretation, not as a summary of the previous findings. In addition, the frequency occurrence of the three moves in the local LRs shows that Move 1 was the most favored move; it occurred as three times as the frequency counts of Moves 2 and 3. This indicates how the writers of the local LRs view the LR as a means to display their grasp of the literature relevant to the issue under investigation. In addition, their minimal use of Moves 2 and 3 may reflect the main obstacle that hinders them from publishing internationally. This obstacle prevents them from highlighting the research gap within the literature (Move 2) and clarifying their own contribution to the literature (Move 3). Finally, the low ratio of Move 3 compared to the first two moves in both sub-corpora can be attributed to its possible occurrence in other sections of the RA such as the introduction, results, discussion, or conclusion. Unlike Kwan's findings, the three moves were obligatory in the international sub-corpus. In contrast, only Move 1 was obligatory and Moves 2 and 3 were prototypical in the local sub-corpus.

4.2.2 Step Distribution Across Both Sub-Corpora.

4.2.2.1 Move 1 Steps. Table 5 shows a total of 80 occurrences of Move 1 steps in the international sub-corpus and 44 occurrences in the local sub-corpus.

Table 5. Frequency Counts of Move 1 Steps across both Sub-corpora

\begin{tabular}{lcccc}
\hline Move 1 steps & \multicolumn{2}{c}{ No. of instances } & \multicolumn{2}{c}{ No. of LRs } \\
& Local & International & Local & International \\
\hline
\end{tabular}




\begin{tabular}{lrrll}
\hline Step 1.1 & 17 & 19 & 4 & 4 \\
Step 1.2 & 9 & 10 & 4 & 4 \\
Step 1.3 & 3 & 7 & 2 & 3 \\
Step 1.4 & 8 & 26 & 3 & 5 \\
Step 1.5 & 2 & 15 & 1 & 3 \\
Step 1.6 & 5 & 3 & 2 & 1 \\
\hline Total & 44 & 80 &
\end{tabular}

Table 5 reveals that Step 1.4 was the most used step in the international sample, and Step 1.1 was the most used step in the local sample. This indicates that Move 1 is mainly realized through these two steps. They were followed by Steps 1.5, 1.2, and 1.3 in the international dataset. Steps 1.3 and 1.5 represent the least frequent steps in the local sub-corpus; they are even less than Step 1.6, which represents the least frequent step in the international dataset.

The findings reveal that the international sub-corpus involved one obligatory step (1.4), four prototypical steps $(1.1,1.2,1.3, \& 1.5)$, and one optional step (1.6). As for the local sub-corpus, there were three prototypical steps $(1.1,1.2, \& 1.4)$ and three optional ones $(1.3,1.5, \& 1.6)$.

4.2.2.2 Move 2 Steps. A total of 42 occurrences of Move 2 steps were identified in the international subcorpus, and 8 occurrences were identified in the local sub-corpus as shown in Table 6.

Table 6. Frequency Counts of Move 2 Steps across both Sub-corpora

\begin{tabular}{lllll}
\hline Move 2 steps & \multicolumn{2}{c}{ No. of instances } & \multicolumn{2}{c}{ No. of LRs } \\
& Local & International & Local & International \\
\hline Step 2.1A & 2 & 20 & 2 & 5 \\
Step 2.1B & 4 & 7 & 3 & 3 \\
Step 2.2 & - & 6 & - & 3 \\
Step 2.3 & 2 & 9 & 1 & 4 \\
\hline Total & 8 & 42 & &
\end{tabular}

Table 6 reveals that Sub-step 2.1A occurred the most in the international dataset, followed by Step 2.3 and Sub-step 2.1B, which represented the most frequent sub-step in the local sub-corpus. This reflects the importance of Step 2.1 (justifying one's research) in general since it represents the core of the whole research, showing how one's research contributes to the literature. It represents the key instigator beyond selecting a particular issue for investigation and the main motivation for the research community to acknowledge and accept one's research. Step 2.1 is considered as the most common realization of Move 2.

All Move 2 steps occurred in the international sub-corpus five times the number found in the local one, reflecting the local writers' lack of training and awareness to use the skills and conventions required to express Move 2. Findings indicate that the Egyptian writers who published internationally are aware of the sophisticated nature of the LR as a process which involves critiquing the literature to highlight the value and originality of one's own research, establishing relations between the previous findings and the research under investigation, and collecting pieces of the literature to adopt a new perspective or develop an argument that constructs the basis for one's own research.

Step 2.1 was classified as obligatory in the international sub-corpus and as prototypical in the local one. Steps 2.2 and 2.3 were prototypical in the international sub-corpus, but they were optional in the local sub-corpus.

4.2.2.3 Move 3 Steps. A total of 25 occurrences of Move 3 steps were identified in the international, and there were 5 occurrences in the local sub-corpus.

Table 7. Frequency Counts of Move 3 Steps across both Sub-corpora

\begin{tabular}{lcccc}
\hline Move 3 steps & \multicolumn{2}{c}{ No. of instances } & \multicolumn{2}{c}{ No. of LRs } \\
& Local & International & Local & International \\
\hline
\end{tabular}




\begin{tabular}{lcccc}
\hline Step 3.1 & 3 & 14 & 2 & 5 \\
Step 3.2 & 2 & 3 & 2 & 3 \\
Step 3.3 & - & 6 & - & 5 \\
Step 3.4 & - & 1 & - & 1 \\
Step 3.5 & - & 1 & - & 1 \\
\hline Total & 5 & 25 & &
\end{tabular}

Table 7 reveals that Step 3.1 was the most favored step across both sub-corpora. Its frequency counts in the international subset exceeded the frequency counts of the other four steps. This indicates its importance and makes it the strongest realization of Move 3. It was followed by Steps 3.3, 3.2, 3.4, and 3.5 in the international LRs. In general, move 3 steps were rarely used in the local subset.

There were two obligatory Steps (3.1 \& 3.3), one prototypical Step (3.2), and two optional Steps (3.4 \& 3.5) in the international sub-corpus. As for the local sub-corpus, there were only two optional steps $(3.1 \& 3.2)$ and the other steps did not show up.

\section{Discussion}

Agreeing with the three major studies on the LR (Hsiao \& Yu, 2012; Jian, 2010; Kwan, 2006), Moves 1 and 2 were the most frequent moves and Move 3 occurred the least. In line with Chen and Kuo's (2012) findings, Steps 1.1 (Surveying the non-research-related phenomena or knowledge claims), 1.4 (Surveying the researchrelated phenomena), 2.1 (Justifying one's research), and 3.1 (Highlighting research aims, focuses, research questions/hypotheses, or contribution/significance) were the most frequent steps within their corresponding moves. These findings reflect the importance of the first two moves compared to Move 3, where Step 3.1 is its strongest realization.

Unlike the three major studies, Step 1.4 occurred the most in Move 1 in the international LRs. However, Step 1.1 was the most common step in the local sub-corpus, agreeing with most previous findings (Hsiao \& Yu, 2012; Jian, 2010; Kwan, 2006; Maulid, 2017; Xie, 2017). Agreeing with Kwan's findings, Step 2.1 represented the most frequent step within its corresponding move in both sub-corpora. However, Sub-step 2.1A (providing negative justification) was the most used one in the international subset and Sub-step 2.1B (providing positive justification) was the most used one in the local subset. This indicates that the Egyptian writers who published internationally were more likely to critique the literature and express its weaknesses than their counterparts who published locally. In accordance with several previous studies (Jomaa \& Bidin, 2017, Kafes, 2017; Xie, 2017; Yağiz, Ötügen, Kaya, \& Aydin, 2014), the locally published writers' - as well as their novice and non-native counterparts' - avoidance of expressing stance and critiquing the literature may be attributed to cultural influences and their lack of academic expertise and linguistic competence. This avoidance of confrontation weakens the value and contributions of their studies and thus affects their credibility. In contrast, the frequency counts of Step 2.3 (Abstracting or synthesizing knowledge claims to establish a theoretical position or a theoretical framework) were inconsistent with the frequency counts in Kwan's (2006) study. While it was the second common step in its corresponding move in both corpora in the current study, it was the least used strategy in Kwan's sample.

The present findings are also in accordance with Hsiao and Yu's (2015) and Hsiao's (2016) findings that the internationally published writers used all the moves and used the Sub-moves of 2A (Grouping and drawing ideas from source materials to gain a new perspective), 3B (Indicating a gap), and 4A (Announcing the aim of the research) much more than their local counterparts. The locally published LRs are also similar to the Spanish ones in Gil-Salom and Soler-Monreal's (2014) study since both involved fewer strategies in Moves 2 and 3 than the internationally published and English LRs, respectively.

Another major difference between both sub-corpora is the moves' classification as obligatory, prototypical, or optional. Unlike Kwan's model where none of the moves was obligatory, the three moves were obligatory in the international sub-corpus. The findings partially agree with Soler-Monreal's (2015) findings where the three moves were obligatory in the English LRs written by English and Spanish writers, while Moves 1 and 2 were obligatory and Move 3 was optional in the Spanish LRs. Aligned mostly with Xie's findings, Move 1 was obligatory and Move 3 was prototypical in the local LRs. However, Move 2 was obligatory in Xie's study and was prototypical in the current study. 


\section{Conclusion}

The current study was after digging deep into the reasons why particular Egyptian-authored LRs are published internationally, while others fail to meet the criteria. From a genre perspective, the study analyzed and compared the rhetorical structure of a sample of 10 Egyptian-authored linguistics RA LRs published locally and internationally, adopting genre-based and corpus-driven approaches. Based on quantitative and qualitative analyses, the findings revealed that Move 1 (Establishing one part of the territory of one's own research), Move 2 (Creating a research niche), and Move 3 (Occupying the research niche) were obligatory moves in the international LRs. In contrast, Move 1 was the only obligatory move in the local LRs, while Moves 2 and 3 were prototypical moves. In addition, the writers in the international LRs used more steps than their counterparts in the local LRs, especially Move 2 and Move 3 steps. While all the steps of the three moves occurred in the international sub-corpus, one out of Move 2 three steps (Step 2.2) and three out of Move 3 five steps (Steps 3.3, 3.4, \& 3.5) did not show up in the local sub-corpus and the other two steps of Move 3 occurred in only two local LRs. These findings indicate that the writers of the international LRs are more aware of genre knowledge than their counterparts of the local LRs (i.e., identifying the LR's moves and subsequent steps and reflecting their rhetorical functions). It can be argued that their development of genre knowledge is because they were exposed to another type of academic instruction that pays more attention to genre knowledge in academic writing and guides learners on using appropriate rhetorical features.

The findings suggest many pedagogical implications for novice and non-native researchers and EAP course designers and instructors. The variation in both sub-corpora shows the need to improve the Egyptian researchers' mastery of genre knowledge to avoid the drawbacks in the local RA LRs. In addition, investigating English writing by non-native researchers in writing and publishing RAs enriches the context of English as a lingua franca (ELF) that is oriented towards a hybrid research community that involves writers and readers of different languages and cultures (Wu, Mauranen, \& Lei, 2020). Finally, the modified Kwan's model for analyzing the rhetorical structure of RA LRs is considered as the main contribution of the current study. It contributes to a better understanding of the genre structure of effective RA LRs. Egyptian researchers must learn to apply the three moves which are obligatory in the international RA LRs.

Given the limited corpus size and its specialization in one section and one discipline written by only Egyptian writers, further research on a larger corpus of complete RAs written by Egyptian and international writers across different disciplines is needed to enrich the researchers' genre knowledge. It is recommended to investigate RA LRs at the micro level through investigating their linguistic features. Finally, better understanding of the differences between both sub-corpora can be achieved and more assistance can be offered to the Egyptian writers by holding interviews with the writers in both sub-corpora to identify their preferences in using particular features and to highlight the challenges they face when writing their RA LRs and other sections. Additional interviews with editors and reviewers in both sub-corpora can reveal the most recurrent pitfalls committed by writers when submitting their manuscripts for publication. These interviews can also identify the areas of concern and how the acceptance/rejection criteria of anglophone reviewers deviate from those of their non-anglophone counterparts. 
Appendix $A$

List of Research Articles in the Local and International Sub-corpora

(Loc1)

Emara, I. (2017). Gender identity construction in facebook statuses of Egyptian young adults. Cairo Studies in English, 2017(1). 86-111.

(Loc2)

Badr, N. O. A. (2016). A linguistic study of humor in Bassem Youssef's "Al Bernameg" and Jon Stewart's "The Daily Show": A multi-modal integrated approach. Journal of Scientific Research in Arts, 2(17-3), 1-42.

(Loc3)

Gad, R. F. (2018). An eco-linguistic account of press real estate advertisements in Egypt. Bulletin of the Faculty of Languages \& Translation, 15(Foreign Section), 239-298.

(Loc4)

El Attar, A. (2017). Metaphoric Blends in Online Cartoons on Egypt's Education System. Philology, 34(68), 61-96.

(Loc5)

Bekheet, M. M. S. (2019). Muslim Representation in Post 9/11 Hollywood: A Semio-Pragmatic Analysis. Journal of the Faculty of Arts \& Humanities, Suez Canal University, 2(29), 216-253.

(Int1)

Azaz, M. (2019). L1 transfer effects in the production of generic plurals in L2 Arabic. The Modern Language Journal, 103(1), 275-290.

(Int2)

Mohamed, A. A. (2018). Exposure frequency in L2 reading: An eye-movement perspective of incidental vocabulary learning. Studies in Second Language Acquisition, 40(2), 269-293.

(Int3)

Ibrahim, K. (2019). Foreign language practice in simulation video games: An analysis of game-based FL use dynamics. Foreign Language Annals, 52(2), 335-357.

(Int4)

Morkus, N. (2014). Refusals in Egyptian Arabic and American English. Journal of Pragmatics, 70, 86-107.

(Int5)

Shaalan, K, Magdy, M., \& Fahmy, A. (2013). Analysis and feedback of erroneous Arabic verbs. Natural Language Engineering, 21(2), 271-323. 
Appendix $B$

Examples on The Steps of The Three Moves from Both Sub-Corpora

\begin{tabular}{l}
\hline Moves \\
\hline Move 1 \\
Establishing one part of the \\
territory of one's own research
\end{tabular}

\section{Step 1.1}

Surveying the non-research related phenomena or knowledge claims

Step 1.2

Claiming centrality

Step 1.3

Approaching a different (sub)theme and summarizing a group of relevant previous studies

\section{Step 1.4}

Surveying the research-related Phenomena

\section{Step 1.5}

Evaluating previous studies

\section{Step 1.6}

Outlining the structure of the $L R$

\section{Move 2}

\section{Creating a research niche}

\section{Sub-step 2.1A}

Providing negative justification
Examples from both sub-corpora

"The DCT was first developed by Blum-Kulka (1982) and it typically consists of ... There are two types of role plays that have been identified in the literature: ...." (Int4)

"Since 9/11 many television shows, programs, and films tackled the issue of terrorism, ... Since September 11, 2001, much of American and world politics, governments and media have focused on the issues of Muslim terrorism and extremism, especially in the Middle East region." (Loc5)

"A number of empirical studies have found a strong relationship between digital gaming and FL learning (Jensen, 2017; Sundqvist \& Wikström, 2015; Sylvén \& Sundqvist, 2012)." (Int3)

"Abdel-Raheem (2016) adopts Fauconnier and Turner's (1998) conceptual blending theory to analyze.... In another study, Coulson (2005) applies Fauconnier and Turner's (2002) conceptual integration on a radio call-in show...." (Loc4)

"The classic study of Saragi, Nation, and Meister (1978) used the novel A Clockwork Orange (1962) by Anthony Burgess. It was of particular interest because it included Russian slang words, referred to as Nadsat, which served as the targets in the authors' reading experiment." (Int2)

"This section describes the forms and functions of humor and presents the traditional theories of humor as well as the multimodal discourse approach." (Loc2)

" $<$ Sub-S2.1A $>$ The very limited existing literature on definiteness in Arabic reports errors in the definite article as part of surveying common errors in writing in general, with no systematic investigations that tease apart the underlying reasons for these errors ....." (Int1) 
Sub-step 2.1B

Providing positive justification

Step 2.2

Asserting the relevancy of the surveyed claims to one's own research

\section{Step 2.3}

Abstracting or synthesizing knowledge claims to establish a theoretical position or a theoretical framework

Move 3

Occupying the research niche

\section{Step 3.1}

Highlighting research aims, focuses, research questions/hypotheses, or contribution/significance

Step 3.2

Positing theoretical positions/theoretical

frameworks

Step 3.3

Presenting research

design/processes

Step 3.4

Evaluating the present research

\section{Step 3.5}

Providing interpretations of the terminology used in the current research
"Godfroid and colleagues (2013) extended the eye-movement investigation to longer, more coherent paragraphs. Twentyeight advanced EFL learners read 12 short paragraphs with target words.... This study is innovative in L2 vocabulary research by bringing attention to a robust method of quantifying the cognitive processes underlying incidental learning." (Int2)

" $<$ S2.2> Based on this review of the literature, two important observations relevant to the purpose of the present study have surfaced." (Int1)

$"<\mathrm{S} 2.3>$ This brief survey of the literature on digital gamebased FL learning demonstrates that digital games, especially simulation video games, hold great potential for FL practice and learning, $<$ Sub-S2.1A $>$ but additional research is needed to tap into...." (Int3)

"The present study contributes to the literature in two ways. First, it seeks to establish whether persistent L1 transfer ...." (Int1)

"In an attempt to fill in a certain gap in previous studies, this paper addresses ..., adopting Fauconnier and Turner's (2002) framework of conceptual blending and Grady's (2005) specifying features of metaphoric blends." (Loc4)

"The present study also examined the same issues but instead of analyzing data consisting of single-turn responses, it analyzed interactional, multi-turn data, elicited by the role play method." (Int4)

"The proposed system successfully handles single error words but restricts the handling of multiple error diagnosis. It handles multiple errors that fall under the same lexical error class." (Int5)

"This article uses the terms gameplay, digital gaming, and player-game interaction interchangeably to refer to participants' engagement in stand-alone FL simulation video gaming." (Int3) 


\section{References}

Amnuai, W. (2019). Analyses of rhetorical moves and linguistic realizations in accounting research article abstracts published in international and Thai-based journals. SAGE Open, 9(1), 1-9. https://doi.org/10.1177/2158244018822384

Amnuai, W., \& Wannaruk, A. (2013). Investigating move structure of English applied linguistics research article discussions published in international and Thai journals. English Language Teaching, 6(2), 113. https://doi.org/10.5539/elt.v6n2p1

Anderson, L. W., Krathwohl, D. R., Airasian, P. W., Cruikshank, K. A., Mayer, R. E., Pintrich, P. R., ... Wittrock, M. C. (Eds.). (2001). A taxonomy for learning, teaching, and assessing: A revision of Bloom's taxonomy of educational objectives (abridged ed.). New York: Longman.

Anthony, L. (2017). AntFileConverter (Version 1.2.1) [Computer Software]. Tokyo, Japan: Waseda University. Retrieved from https://www.laurenceanthony.net/software/antfileconverter/

Badenhorst, C. M. (2018). Graduate student writing: Complexity in literature reviews. Studies in Graduate and Postdoctoral Education, 9(1), 58-74.

https://doi.org/10.1108/SGPE-D-17-00031

Baker, P. (2010). Sociolinguistics and corpus linguistics. Edinburgh: Edinburgh University Press.

Basturkmen, H. (2009). Commenting on results in published research articles and Masters dissertations in language teaching. Journal of English for Academic Purposes 8(4), 241-251. https://doi.org/10.1016/j.jeap.2009.07.001

Basturkmen, H. (2012). A genre-based investigation of discussion sections of research articles in dentistry and disciplinary variation. Journal of English for Academic Purposes, 11(2), 134-144. https://doi.org/10.1016/j.jeap.2011.10.004

Bhatia, V. K. (1993). Analysing genre: Language use in professional settings. London: Longman.

Bhatia, V. K. (1997). Introduction: Genre analysis and world Englishes. World English, 16(3), 313-319. https://doi.org/10.1111/1467-971X.00066

Bhatia, V. K. (2012). Critical reflections on genre analysis. Ibérica, (24), 17-28.

Biber, D., Connor, U., \& Upton, T. (2007). Discourse analysis and corpus linguistics. In D. Biber, U. Connor, \& T. Upton (Eds.), Discourse on the move: Using corpus analysis to describe discourse structure (pp. 1-20). Amsterdam: John Benjamins.

Boote, D. N., \& Beile, P. (2005). Scholars before researchers: On the centrality of the dissertation literature review in research preparation. Educational Researcher, 34(6), 3-15. https://doi.org/10.3102/0013189X034006003

Bunton, D. (2002). Generic moves in Ph.D. thesis introductions. In J. Flowerdew (Ed.), Academic discourse (pp. 57-75). London: Pearson Education.

Chen, T. Y., \& Kuo, C. H. (2012). A genre-based analysis of the information structure of Master's theses in applied linguistics. Asian ESP Journal, 8(1), 24-52.

Cooper, H. M. (1985). A taxonomy of literature reviews. The Annual Meeting of the American Educational Research Association. The Literature Review: Knowledge Synthesis Activities in Education and Psychology (pp. 1-46). Chicago: National Inst. of Education.

Cotos, E., Huffman, S., \& Link, S. (2017). A move/step model for methods sections: Demonstrating rigour and credibility. English for Specific Purposes, 46, 90-106. https://doi.org/10.1016/j.esp.2017.01.001

Denney, A. S., \& Tewksbury, R. (2013). How to write a literature review. Journal of Criminal Justice Education, 24(2), 218-234. https://doi.org/10.1080/10511253.2012.730617

Farnia, M. Baratizade, S. (2020). Genre analysis of the method sections in applied linguistics research articles: A cross-linguistic study. Asian ESP Journal, 16(6.1), 214-248.

Feak, C. B., \& Swales, J. M. (2009). Telling a research story: Writing a literature review. Ann Arbor: The University of Michigan Press.

Fink, A. (2014). Conducting research literature reviews from the internet to paper ( $4^{\text {th }}$ ed.). London: Sage Publications. 
Flowerdew, J. (2001). Attitudes of journal editors to nonnative speaker contributions. TESOL Quarterly, 35(1), 121-150. https://doi.org/10.2307/3587862

Flowerdew, J., \& Wang, S. H. (2016). Author's editor revisions to manuscripts published in international journals. Journal of Second Language Writing, 32, 39-52. https://doi.org/10.1016/j.jslw.2016.03.004

Friginal, E., \& Mustafa, S. S. (2017). A comparison of U.S.-based and Iraqi English research article abstracts using corpora. Journal of English for Academic Purposes, 25, 45-57. https://doi.org/10.1016/j.jeap.2016.11.004

Gil-Salom, L., \& Soler-Monreal, C. (2014). Writers' positioning in literature reviews in English and Spanish computing doctoral theses. Journal of English for Academic Purposes, 16, 23-39. https://doi.org/10.1016/j.jeap.2014.08.002

Habibie, P. (2019). To be native or not to be native: That is not the question. In P. Habibie \& K. Hyland (Eds.), Novice writers and scholarly publication: Authors, mentors, gatekeepers (pp. 35-52). London: Palgrave Macmillan.

Ho, D. (2020). Notepad++ (Version 7.8.6) [Computer Software]. Retrieved from https://notepad-plus-plus.org/downloads/v7.8.6/

Hsiao, C. H. (2016). Genre analysis of low-rated and high-rated literature reviews by EFL postgraduates. International Journal of English Language Teaching, 3(1), 1-19. https://doi.org/10.5430/ijelt.v3n1p1

Hsiao, C. H., \& Yu, H. Y. (2012). Knowledge presentation in thesis writing-Examining move use in reviewing literature. English Teaching \& Learning, 36(3), 133-179. http://dx.doi.org/10.6330/ETL.2012.36.3.04

Hsiao, C. H., \& Yu, H. Y. (2015). Move distribution and configuration of literature reviews at four levels. Taiwan International ESP Journal, 7(1), 51-77. https://doi.org/10.6706/TIESPJ.2015.7.1.3

Huang, P., \& Zhang, X. (2016, August). Analysis of thematic progression pattern in LR part of economics doctoral thesis through genre. Paper presented at the Joint International Conference of the 8th International Conference on ESP in Asia \& the 3rd International Symposium on Innovative Teaching and Research in ESP in Japan, Tokyo (Vol. 1, pp. 28-35). Tokyo: UEC IGTEE Research Station. Retrieved from http://www.shilab.bunka.uec.ac.jp/jointesp2016/proceedings/06\%20Huang\%2028to35.pdf

Inoue-Smith, Y. (2020). How to help students excel in reviews of the literature. In Y. Inoue-Smith \& T. McVey (Eds.), Optimizing higher education learning through activities and assessments (pp. 328346). Hershey, PA: IGI Global.

Jahangard, A., Rajabi, A., \& Khalaji, K. (2014). A comparison of moves in conclusion sections of research articles in mechanical engineering and applied linguistics. International Journal of Language Learning and Applied Linguistics World, 5(2), 346-359.

Jian, H. (2010). The schematic structure of literature review in research articles of applied linguistics. Chinese Journal of Applied Linguistics, 33(5), 15-27.

Jomaa, N. J., \& Bidin, S. J. (2017). Perspectives of EFL doctoral students on challenges of citations in academic writing. Malaysian Journal of Learning and Instruction, 14(2), 177-209. https://doi.org/10.32890/mjli2017.14.2.7

Kafes, H. (2017). Citation practices among novice and expert academic writers. Education and Science, 42(192), 441-462. https://doi.org/10.15390/EB.2017.6317

Koester, A. (2010). Building small specialized corpora. In A. O'Keeffe \& M. McCarthy (Eds.), The Routledge handbook of corpus linguistics (pp. 66-79). London: Routledge.

Kurniawan, E., \& Lubis, A. H. (2020). A comparative move analysis on the qualitative and quantitative findings and discussion sections written by EFL undergraduate students. Asian ESP Journal, 16(6.1), 137-162.

Kwan, B. S. C. (2006). The schematic structure of literature reviews in doctoral theses of applied linguistics. English for Specific Purposes, 25(1), 30-55. https://doi.org/10.1016/j.esp.2005.06.001 
Lewin, B. A., Fine, J., \& Young, L. (2001). Expository discourse: A genre-based approach to social science research texts. New York: Continuum.

Lim, J. M.-H. (2011). 'Paving the way for research findings': Writers' rhetorical choices in education and applied linguistics. Discourse Studies, 13(6), 725-749. https://doi.org/10.1177/1461445611421364

Lin, L., \& Evans, S. (2012). Structural patterns in empirical research articles: A cross-disciplinary study. English for Specific Purposes, 31(3), 150-160. https://doi.org/10.1016/j.esp.2011.10.002

Liu, Y., \& Buckingham, L. (2018). The schematic structure of discussion sections in applied linguistics and the distribution of metadiscourse markers. Journal of English for Academic Purposes, 34, 97-109. https://doi.org/10.1016/j.jeap.2018.04.002

Loi, C. K., \& Evans, M. S. (2010). Cultural differences in the organization of research article introductions from the field of educational psychology: English and Chinese. Journal of Pragmatics, 42(10), 2814-2825. https://doi.org/10.1016/j.pragma.2010.03.010

Lu, X., Casal, E., \& Liu, Y. (2020). The rhetorical functions of syntactically complex sentences in social science research article introductions. Journal of English for Academic Purposes, 44, 1-16. https://doi.org/10.1016/j.jeap.2019.100832

Lu, X., Yoon, J., \& Kisselev, O. (2021). Matching phrase-frames to rhetorical moves in social science research article introductions. English for Specific Purposes, 61, 63-83. https://doi.org/10.1016/j.esp.2020.10.001

Maulid, W. O. (2017). The moves and steps in the literature review and discussion sections in the four Master's degree theses. Journal of English Education, 2(1), 51-58.

McEnery, T., \& Hardie, A. (2012). Corpus linguistics: Method, theory, and practice. Cambridge: Cambridge University Press.

McGrath, L., \& Kuteeva, M. (2012). Stance and engagement in pure mathematics research articles: Linking discourse features to disciplinary practices. English for Specific Purposes, 31(3), 161-173. https://doi.org/10.1016/j.esp.2011.11.002

Nhat, T. N. (2019). Insights into international publication: A synthesis of move-based literature on the research article genre. VNU Journal of Foreign Studies, 35(1), 84-98. https://doi.org/10.25073/25252445/vnufs. 4339

Parodi, G. (2010). Rhetorical organisation of textbooks: A "colony-in-loops"? In G. Parodi (Ed.), Academic and professional discourse genres in Spanish (pp. 143-169). Amsterdam: John Benjamins.

Peacock, M. (2011). The structure of the method section in research articles across eight disciplines. Asian ESP Journal, 7(2), 99-124.

Pho, P. D. (2013). Authorial stance in research articles: Examples from applied linguistics and educational technology. Basingstoke, UK: Palgrave Macmillan.

Rewhorn, S. (2018). Writing your successful literature review. Journal of Geography in Higher Education, 42(1), 143-147. https://doi.org/10.1080/03098265.2017.1337732

Samraj, B. (2002). Introductions in research articles: Variations across disciplines. English for Specific Purposes, 21(1), 1-17. https://doi.org/10.1016/S0889-4906(00)00023-5

Sheldon, E. (2011). Rhetorical differences in RA introductions written by English L1 and L2 and Castilian Spanish L1 writers. Journal of English for Academic Purposes, 10(4), 238-251. https://doi.org/10.1016/i.jeap.2011.08.004

Soler-Monreal, C. (2015). Announcing one's work in $\mathrm{PhD}$ theses in computer science: A comparison of move 3 in literature reviews written in English L1, English L2 and Spanish L1. English for Specific Purposes, 40, 27-41. https://doi.org/10.1016/j.esp.2015.07.004

Soler-Monreal, C., Carbonell-Olivares, M., \& Gil-Salom, L. (2011). A contrastive study of the rhetorical organisation of English and Spanish PhD thesis introductions. English for Specific Purposes, 30(1), 4-17. https://doi.org/10.1016/j.esp.2010.04.005

Swales, J. M. (1990). Genre analysis: English in academic and research settings. Cambridge: Cambridge University Press. 
Swales, J. M., \& Lindemann, S. (2002). Teaching the literature review to international graduate students. In A. M. Johns (Ed.), Genre in the classroom: Multiple perspectives (pp. 105-119). Mahwah, NJ: Lawrence Erlbaum Associates.

Tankó, G. (2017). Literary research article abstracts: An analysis of rhetorical moves and their linguistic realizations. Journal of English for Academic Purposes, 27, 42-55. https://doi.org/10.1016/j.jeap.2017.04.003

Tewksbury, R., \& Mustaine, E. E. (2012). Cracking open the black box of the manuscript review process: A look inside justice quarterly. Journal of Criminal Justice Education, 23(4), 399-422. https://doi.org/10.1080/10511253.2011.653650

Thompson, P. (2009). Literature reviews in applied PhD theses: Evidence and problems. In K. Hyland \& G. Diani (Eds.), Academic evaluation: Review genres in university settings (pp. 50-67). New York: Palgrave Macmillan.

Tseng, M.-Y. (2018). Creating a theoretical framework: On the move structure of theoretical framework sections in research articles related to language and linguistics. Journal of English for Academic Purposes, 33, 82-99. https://doi.org/10.1016/j.jeap.2018.01.002

Wu, X., Mauranen, A., \& Lei, L. (2020). Syntactic complexity in English as a lingua franca academic $\begin{array}{llllll}\text { writing. Journal of English for Academic Purposes, } & 43, & 1.13 .\end{array}$ https://doi.org/10.1016/j.jeap.2019.100798

Xie, J. (2017). Evaluation in moves: An integrated analysis of Chinese MA thesis literature reviews. English Language Teaching, 10(3), 1-20.

Yağiz, O., Ötügen, R., Kaya, F., \& Aydin, B. (2014). A literature review analysis of the Turkish scholars' research articles in ELT and applied linguistics. Procedia - Social and Behavioral Sciences, 158, 389-393. https://doi.org/10.1016/j.sbspro.2014.12.105

Yang, R., \& Allison, D. (2003). Research articles in applied linguistics: Moving from results to conclusions. English for Specific Purposes, 22(4), 365-385.

https://doi.org/10.1016/S0889-4906(02)00026-1

Zamani, G., \& Ebadi, S. (2016). Move analysis of the conclusion sections of research papers in Persian and English. Cypriot Journal of Educational Science, 11(1), 9-20.

Hend Rabie is an assistant lecturer at Fayoum University, Egypt. She completed an MA in Applied Linguistics. She is now completing a PhD on academic writing. She has taught EAP and ESP courses for several years.

Deena Boraie is Professor of Practice, vice president for student life at AUC, Past President of the TESOL International Association, and a language testing expert. She has taught research methods at Cairo University for many years. She has published several papers and book chapters on assessment literacy and English as a lingua franca. 